\title{
THE CASCADING CLIMATE CRISIS
}

\section{KEY MESSAGES}

- Risk cascades are where an adverse climatic impact or trend triggers or amplifies a set of risks, including through maladaptive responses.

- Climate risk cascades have already occurred and are set to increase going into the future. Some of these could be non-linear and high impact.

- Risk cascades can occur through a unilinear chain - a 'domino' effect-or when the cascades reinforce the initial risk or driver - a 'spiral' or 'cycle effect. At worst, these can snowball into crises that cross sectors and countries.

- Predicting risk cascades will be inherently difficult, if not impossible. Yet we can likely understand the different pathways they may take, and the thresholds past which they are likely to occur.

- Protecting again risk cascades means faster decarbonisation, supporting the most vulnerable, and building more resilient socio-economic systems. This will require indirect measures, such as remedying inequalities.

\section{INTRODUCTION: A REAL AND RISING RISK}

In 2010, an artic-warming driven heatwave hit Russia, sharply decreasing crop yields. Russia responded by introducing a cereal export ban. Global cereal prices spiked. The price hike contributed to unrest and political change in Egypt, as well as a surge in good bank usage in the UK'.

This is one example of a 'risk cascade' triggered by the impacts of climate change. A direct hazard (heatwave) drives a response (cereal export ban) which in turn amplifies conflict in a vulnerable country (Egypt), and hunger (food banks in the UK) among the poor. Risk cascades are already occurring. They are also set to rise alongside temperatures.

Risk cascades are not unique to climate change. They are common in a complex world. We need to look no further than the COVID-19 pandemic to see that knock-on effects and societal responses can be as damaging as the initial threat. Efforts to 'flatten the curve' of infections were not simply to address the direct hazard of pandemic fatalities. It was an effort to prevent health system collapse. It was an effort to prevent a risk cascade in which the overburdening of the health care system would lead to substantially higher mortality and morbidity from other health issues alongside COVID, as well as the potential for broader impacts and social unrest. Such cascades will be worsened by climate change. Climate hazards, such as wildfires, heatwaves and floods have the potential to compound and aggravate losses from the pandemic ${ }^{2}$.

Climate risk cascades may be real, yet they are also neglected. Complex assessments of risk cascades and responses are sparse. There have been a few recent examples, as well as notable attempts to build risk analysis frameworks ${ }^{3}$. Despite these attempts, most risk assessments of climate change currently have a linear approach of aggregating the damages from different hazards under different scenarios ${ }^{4}$. Even simple 'compound hazard' analysis, in which the interaction of different hazards is consider, is rarely done ${ }^{5}$.

In this technical briefing we will first define and explore risk cascades, discuss how we can understand and assess them, investigate how to build resilience to them, and finally the policy implications. This briefing draws upon a panel on Climate Risk Cascades at the COP26 Universities Climate Risk Summit on the 29th of September 2021. The panel included four leading experts on risk cascades: Professor llona Otto, Professor Aled Jones, Dr Daniel Quiggin and Dr Ellen Quigley.

\section{Author:}

I Dr Luke Kemp, Research Associate, Centre for the Study of Existential Risk (CSER), University of Cambridge. 


\section{WHAT ARE CLIMATE RISK CASCADES?}

\subsection{Defining Risk Cascades}

Despite the reality of risk cascades, they are not defined by the IPCC. They can be thought of as chains of risk in which adverse climatic impact or trend triggers or amplifies a set of risks ${ }^{3}$. This can include maladaptive responses, or as defined by the IPCC 'response risks't. Now, the determinants of risk are hazard, vulnerability, exposure and response ${ }^{3}$.

Risk cascades can take several forms. One is a domino: a single or set of risks trigger or amplify others, which can in turn catalyse or worsen others in a chain reaction. The 2010 Russian heatwave mentioned at the beginning of this briefing is an excellent example of such a domino effect. The other is a spiral or cycle: follow-on effects can reinforce either the risk, or a triggered risk, resulting in an amplifying feedback loop. For instance, climate induced droughts and floods creating food shortages, in turn triggering socio-political conflict, could lead to heightened emissions (both due to military operations and distracting from mitigation), thus worsening climate drivers.

Risk dominos and spirals can be triggered not just by climatic impacts, but also by societal responses to the climate crisis. This includes large-scale efforts to reduce climate impacts through interventions in the Earth system, a process known as geoengineering. Efforts such as stratospheric aerosol injection (SAI- the injection of particles into the atmosphere to reflect sunlight) could have a range of diffuse risks. These include changing disease vectors and range, changes to precipitation and food yields, and even the potential to exacerbate political tensions and conflict (although each of these areas are significantly understudied). Each of these are likely to have further knock-on effects. In the worst case, the sudden disruption of an SAI system could lead to rapid warming-termination shock?

Either risk dominoes or spirals can trigger wider crises. This could occur through risks being perpetuated across borders and sectors ${ }^{8}$. This is increasingly likely in a hyper connected world. For instance, previous floods in Thailand have had significant repercussions for the global supply of both computer hardware and automobile parts. Multiple stressors interacting together, and overwhelming particular systems can trigger 'synchronous failures' in which one system failure reinforces another. One example is the oil price surge of 2008 (due to declining EROI, surging demand and a decline in mature oil field production) intersecting with both a global food price surge and the global financial crisis, aggravating both?. Table 1 provides a summary of the definitions of these different key terms.
Table 1: Defining Different Forms of Risk

\begin{tabular}{|c|c|}
\hline Term & Definition \\
\hline Risk & $\begin{array}{l}\text { The potential for adverse } \\
\text { consequences for human or } \\
\text { ecological systems, recognising } \\
\text { the diversity of values and } \\
\text { objectives associated with such } \\
\text { systems. This includes both the } \\
\text { impacts and human responses } \\
\text { to climate change. }\end{array}$ \\
\hline Response Risk & $\begin{array}{l}\text { Risks incurred by human responses } \\
\text { to climate change }{ }^{6} \text {. }\end{array}$ \\
\hline Risk Cascade & $\begin{array}{l}\text { Chains of risk in which adverse } \\
\text { climatic impact or trend triggers } \\
\text { or amplifies a single or set of risks. } \\
\text { This can include risk responses }{ }^{3} \text {. }\end{array}$ \\
\hline Risk Domino & $\begin{array}{l}\text { A risk cascade in which the initial } \\
\text { risk driver is not reinforced. }\end{array}$ \\
\hline $\begin{array}{l}\text { Risk Feedback } \\
\text { (Spiral/Cycle) }\end{array}$ & $\begin{array}{l}\text { A risk cascade in which the initial } \\
\text { risk driver is reinforced. }\end{array}$ \\
\hline Systemic Risk & $\begin{array}{l}\text { The potential for connected risks } \\
\text { to cause individual disruptions or } \\
\text { failures to cascade into a system- } \\
\text { wide failure }{ }^{10} \text {. At its most extreme } \\
\text { this can result in unbounded } \\
\text { damage }^{11} \text {. }\end{array}$ \\
\hline $\begin{array}{l}\text { Synchronous } \\
\text { Failures }\end{array}$ & $\begin{array}{l}\text { Failures in one system triggering } \\
\text { or exacerbating disruptions to } \\
\text { another, which in turn feedback } \\
\text { and drive the initial system failure. }\end{array}$ \\
\hline
\end{tabular}

The likelihood of risk cascades and crises are not just a product of climatic impacts. They stem from the structure of the global system, as well as the other converging economic, political and ecological stresses that the world is facing ${ }^{12,13}$. A world marked by conflict, political fragmentation and inequality is far more likely to be susceptible to risk cascades than one characterised by international cooperation.

\subsection{Sample Cascades}

There are several known, likely and concerned climate risk cascades, including disease and conflict. Climate conflict looms large in the collective imagination. Book such as 'Climate Wars' have already made some public attempts to scientifically trace how different degrees of warming could cause different levels of violent strife ${ }^{14}$. Past empirical evidence suggest that conflict has a complex causal relationship with climatic impacts. While it depends on the context, climate change can drive both conflict and forced migration, primarily through drought ${ }^{15}$. Climatedisasters do appear to have a direct connection to conflict in case involving low population, ethnic exclusion and low development ${ }^{16}$. 
Shortages in food, fuel, and energy have already proven to be engines of intra and inter-state conflict ${ }^{17}$. How the link between climate and armed conflict, and knock-on effects on population displacement, economic crisis and state failure, unfold under higher temperatures is an area of high uncertainty.

Climate change will increase the range and spread of many vector-borne diseases. For instance, malaria transmission is expected to increase in range, particularly for tropical highlands ${ }^{18}$. Other research suggest that warming will increase the environmental suitability of arboviruses such as dengue and chikungunya, rather than malaria ${ }^{19}$. Regardless of the exact risk profile, the overall global disease burden is likely to both shift and worsen, with knock-on effects on effected populations, the suitability of existing healthcare strategies, and even the stability of healthcare systems. In the worst cases, climate change could even contribute to the spill-over of new zoonotic infections into humans ${ }^{20}$. As we have seen with the COVID-19 virus, the potential risk cascades of a novel zoonotic infection are manifold and immense.

These is just a small sample of some prominent climate risk cascades. They are based largely on existing empirical examples, but how they will unfold at higher amounts or rates of warming is unknown. These cascades should be thought of as neither inevitable nor separate. They are probabilistic and interlinked.

\section{UNDERSTANDING AND PREDICTING RISK CASCADES 2.1 Exploring the Pathways}

Climate risk cascades are a nascent area of study. They are significantly understudied compared to individual hazards such as sea-level rise, or even compound hazards such as the exacerbating effect of a hurricane (wiping out electrical infrastructure) followed by a heatwave. Fortunately, they are also an area of burgeoning study, particularly in recent years.

While the literature is embryonic, there are many suggestions of how to study risk cascades. Challinor et al suggest that the most promising tools for understanding the transmission of climate risks across borders and sectors are expert judgement, interactive scenarios, big data and systems science, and modified integrated assessment models (IAMs) ${ }^{8}$. Others have similarly suggested that complex climate risk assessment should make use of systems mapping (causal loop diagrams), expert elicitation and participatory scenarios. Some have even put forward specific methods of using interviews and workshops to construct causal loop diagrams of systems cascades ${ }^{21}$.
To date, most efforts to explore risks cascades have used systems mapping and expert elicitation. Expert elicitation provides a flexible way of deciphering and understanding risk cascades. Such methods often rely on a process of deliberative democracy among experts. In it, experts exchange information in structured ways to improve their judgement. These are then used to perform tasks such as make forecasts or map beliefs. One recent example is a Chatham House exercise involving approximately seventy experts ${ }^{22}$.

Systems dynamics maps provide a promising way of unravelling and depicting risk cascades. These maps depict systems of feedback and chains of cause and effect that drive the behaviour of a system. In other words, they are ways to visually portray and decipher domino and spiral effects. Such mapping exercises have been used for an array of problems, from critiquing international climate agreement ${ }^{23}$, to understanding 'Anthropocene risks' such as stranded assets ${ }^{24}$. The most comprehensive and promising study to date used 41 studies to empirically map the connections between climate change, food insecurity and societal collapse (population loss through conflict, mortality and emigration $)^{25}$. Such maps usually rely on individual or group expert elicitation. They can also provide the basis for eventual quantitative or semi-quantitative models.

\subsection{Quantifying the Risk}

Precise numerical estimates of the likelihood or severity of risk cascades will be challenging, if not impossible. In short, foresight (understanding plausible future pathways) is possible, but forecasting (specific quantitative estimates of events) may not be. Putting quantitative estimates on risk cascades may be foolish, but it will still almost certainly be done. Many financial products, most notably insurance, require such precise quantifications of risk. Highly accurate estimates for risk cascades and responses are unlikely. Yet there are less and more reliable ways of calculating probabilistic ranges for risk cascades. Ideally, pricing financial products should consider the full array of risks, including cascades. This will only make for a more accurate pricing method. If this is to be done, it should draw on the state-of-the-art methods discussed: expert judgement and systems dynamics models. One way of doing so would be to leave large ranges for probability and severity, rather than trying to reach a single definitive figure.

While precise probabilities may be challenging, understanding pathways and thresholds. Elucidating pathways is the main attraction of systems dynamics approaches to risk cascades. They provide a collective view of how the cascade could unfold, chains of reinforcing feedback and leverage points. 
Understanding threshold effects is another achievable way to foresee risk cascades. Many socio-political systems operate possess social tipping points in which reinforcing feedback loops can result in a small quantitative change resulting in a (sometimes irreversible shift) to a new system state. Researchers have already begun to research how positive social tipping points and cascade effects could drive decarbonisation ${ }^{26}$. Understanding such thresholds also requires knowledge of how exactly social change occurs ${ }^{27}$. Understanding these thresholds and the spirals that drive them are part of a broader effort to understand 'critical transitions' in complex systems ${ }^{28,29}$. While incipient, such research and approaches can help us to foresee potential risk cascades, and how they can result in broader crises and structural shifts. This may not result in precise probabilities, but rather early warning signals, and thresholds (of warming or other variables) that make risk cascades disproportionately likely and intense.

\section{BUILDING RESILIENCE TO RISK CASCADES}

Building resilience to risk cascades is a devilish task. The risks are partly unpredictable. This makes designing specific resilience measures challenging. Since they involve long chains of cause and effect across sectors and countries, then resilience measures will require international cooperation and responses that cut across government departments. Since the impacts could be non-linear and extreme, it will require precautionary action. Nonetheless there are ways to increase societal resilience to risk cascades.
First, is to simply reduce exposure. The lower the rate and magnitude of warming the smaller the impacts. There will be more, and graver risk cascades incurred by $2^{\circ} \mathrm{C}$ of warming rather than $4^{\circ} \mathrm{C}$. This simply buttresses the overwhelming case for accelerating global decarbonisation.

Second, is to support areas in the global system that are likely to be the origins of risk cascades. The poorest, most politically fragile regions of the world, are likely to be those most impacted by climate change $\mathrm{e}^{30}$. This overlap between vulnerability and impacts makes these areas far more likely to be the site of state failure, famine, displacement, and general socio-political upheaval. This underscores the need for pre-emptive action through finance, capacity building and adaptation. The best way to stop a risk cascade is to ensure the initial risk never happens. Keep the first domino standing.

Third, is to build more resilient socio-economic systems in general. In the language of socioecological resilience theory this is 'general resilience' rather than 'specific resilience': building the capacity to withstand, adapt and respond to a broad suite of risks, rather than a few particular, select threats. There are a multitude of ways to build societal resilience. Below in Table II is a short summary of some of the key principles of resilience identified in the literature, as well as example application to climate risk cascades. Increasing general resilience is still a topic of debate and the operation of some principles is complex.

\section{Table 2: General Resilience Principles}

\begin{tabular}{|c|c|c|}
\hline Principles & Description & Example Application \\
\hline $\begin{array}{l}\text { Adaptive } \\
\text { Capacity }\end{array}$ & $\begin{array}{l}\text { The ability for a society to change existing } \\
\text { behaviour based on observation and (social } \\
\text { and organizational) learning to better fit the } \\
\text { environment. }\end{array}$ & $\begin{array}{l}\text { Eco-system-based adaptation by local } \\
\text { communities to respond to climate impacts. }\end{array}$ \\
\hline Diversity & $\begin{array}{l}\text { Diversity refers to the variety of elements } \\
\text { in a system, the balance between different } \\
\text { elements and their disparity (how much } \\
\text { elements differ from one and other). }\end{array}$ & $\begin{array}{l}\text { Diversifying the supply chain of crops } \\
\text { to ensure that a country is not overly } \\
\text { dependent on a single staple or source. }\end{array}$ \\
\hline $\begin{array}{l}\text { Inter- } \\
\text { connectedness }\end{array}$ & $\begin{array}{l}\text { The number and intensity of linkages between } \\
\text { different elements of a system. This can range } \\
\text { from information (social connections, sharing } \\
\text { of administrative data) through to material } \\
\text { (trade) flows. }\end{array}$ & $\begin{array}{l}\text { Slowing and regulating financial trade } \\
\text { to prevent capital flight and the quick } \\
\text { contagion of financial crises. }\end{array}$ \\
\hline Modularity & $\begin{array}{l}\text { Modularity measures how densely connected } \\
\text { 'hubs' within a network can be decoupled. } \\
\text { A network is usually more robust if a key node } \\
\text { can be destroyed with little impact on the } \\
\text { remaining network. }\end{array}$ & $\begin{array}{l}\text { Breaking the energy grid into smaller, } \\
\text { modular sub-components. The failure of } \\
\text { any small grid can never spiral into a nation- } \\
\text { wide blackout. }\end{array}$ \\
\hline Redundancies & $\begin{array}{l}\text { Repeated and replicated components within } \\
\text { a system. Like kidneys, if one fails, another } \\
\text { can take over. }\end{array}$ & $\begin{array}{l}\text { Keeping adequate reserves of staple crops } \\
\text { and critical resources in case of a price } \\
\text { shock or the severing of a supply line. }\end{array}$ \\
\hline
\end{tabular}

Source: adapted from Kemp and Cline ${ }^{31}$, compiled from multiple sources ${ }^{32-34}$. 
For instance, highly interconnected systems are more capable of buffering against small shocks, but also more likely to amplify sufficiently large disruptions ${ }^{28}$. The globalised world means aid can flow between countries quickly in times of disasters. But it also means viruses can travel at the speed of an airplane, and financial data within seconds.

One approach to building societal resilience. is to address inequalities, especially in wealth. Wealth inequality has been linked to a plethora of social ills ranging from teenage pregnancy and crime, through to environmental degradation and violence ${ }^{35}$. The effects even stretch into mental health. Countries with higher wealth inequality exhibit higher levels of a host of mental pathologies, stress, and lower levels of wellbeing ${ }^{36}$. There are also, increasingly well-documented links between inequality and corruption ${ }^{37}$. The two appear to exist in a feedback loop. Corruption can compel higher levels of inequality and vice-versa ${ }^{38}$. Perhaps most worryingly, wealth inequality has been linked to higher levels of political polarisation. Such inequality driven polarisation can, at worst, lead to the erosion of democratic institutions ${ }^{39}$. Other inequalities can also be destructive. For instance, ethnically divided countries are more likely to have climatic impacts amplify or spark armed conflict ${ }^{40}$. Improving equality, whether it be through redistribution, criminal justice reforms, or addressing tax evasion, will help to build societies that are more resilient to risk cascades of any form.

\section{IMPLICATIONS FOR POLICY}

Risk cascades have several important policy implications. First, they require governments and organisations to adopt more complex forms of risk assessment. This should include the use of expert elicitation and systems mapping to understand risk cascades, risk responses (not just vulnerabilities, exposures, and hazards) and drivers. Such methods could even provide insights into potential social tipping points to be avoided. While quantifying such risks is deeply difficult, it will almost certainly be done for financial products. Again, this should draw on this more nuanced, complex forms of risk assessment.

Second, knowledge of risk cascades should underline the need for rapid emissions reductions. We do not know how risk cascades will unfold under higher temperatures or even climatic tipping points. However, evidence points towards them becoming more frequent and severe, potentially in a nonlinear manner.

Third, adaptation and resilience efforts should be guided by an awareness of potential risk cascades. Finance to the most vulnerable is already a pressing concern, risk cascades provide yet another reason. Understanding what areas and sector are the most likely to be the origin of a risk cascade could help to better target adaptation, capacity-building, and finance efforts. Whether it be state failure, conflict, or disease spill over, forewarned is forearmed. The upside is that many of the measures to build resilience against risk cascades, such as reducing inequalities, are already social goals we should be pursuing. Risk cascades reveal that often climate justice is resilience.

\section{REFERENCES}

1. Hildén, M. et al. Cascading climate impacts: a new factor in European policy-making. 1-4 https://ecdpm. org/cascading-climate-risks-towards-adaptiveresilient-european-societies/ (2020).

2. Phillips, C. A. et al. Compound climate risks in the COVID-19 pandemic. Nat. Clim. Change 10, 586-588 (2020).

3. Simpson, N. P. et al. A framework for complex climate change risk assessment. One Earth 4, 489-501 (2021).

4. Lawrence, J., Blackett, P. \& Cradock-Henry, N. A. Cascading climate change impacts and implications. Clim. Risk Manag. 29, 100234 (2020).

5. Zscheischler, J. et al. Future climate risk from compound events. Nat. Clim. Change 8, 469-477 (2018).

6. IPCC. The concept of risk in the IPCC Sixth Assessment Report: a summary of cross-Working Group discussions. 1-15 www.ipcc.ch/site/assets/uploads/2021/02/Riskguidance-FINAL_15Feb2021.pdf (2020).

7. Tang, A. \& Kemp, L. A Fate Worse Than Warming? Stratospheric Aerosol Injection and Catastrophic Risk. Front. Clim. 3, (2021).

8. Challinor, A. J. et al. Transmission of climate risks across sectors and borders. Philos. Trans. R. Soc. Math. Phys. Eng. Sci. 376, 20170301 (2018).

9. Homer-Dixon, T. et al. Synchronous failure: the emerging causal architecture of global crisis. Ecol. Soc. 20, art6 (2015).

10. Centeno, M. A., Nag, M., Patterson, T. S., Shaver, A. \& Windawi, A. J. The Emergence of Global Systemic Risk. Annu. Rev. Sociol. 41, 65-85 (2015).

11. United Nations. International Stratety for Disaster Reduction. Secretariat. Global Assessment Report on Disaster Risk Reduction 2015: Making Development Sustainable: the Future of Disaster Risk Management. vol. 4 (UN, 2015).

12. Ahmed, N. M. Failing States, Collapsing Systems: BioPhysical Triggers of Political Violence. (Springer International Publishing: Imprint: Springer, 2017). doi:10.1007/978-3-319-47816-6.

13. Homer-Dixon, T. The Upside of Down: Catastrophe, Creativity, and the Renewal of Civilization. (Island PR, 2008).

14. Dyer, G. Climate Wars the Fight for Survival as the World Overheats. (Oneworld, 2011).

15. Abel, G. J., Brottrager, M., Crespo Cuaresma, J. \& Muttarak, R. Climate, conflict and forced migration. Glob. Environ. Change 54, 239-249 (2019).

16. Ide, T., Brzoska, M., Donges, J. F. \& Schleussner, C.-F. Multi-method evidence for when and how climaterelated disasters contribute to armed conflict risk. Glob. Environ. Change 62, 102063 (2020). 
17. Natalini, D., Bravo, G. \& Jones, A. W. Global food security and food riots - an agent-based modelling approach. Food Secur. 11, 1153-1173 (2019).

18. Caminade, C. et al. Impact of climate change on global malaria distribution. Proc. Natl. Acad. Sci. 111, 3286 (2014).

19. Mordecai, E. A., Ryan, S. J., Caldwell, J. M., Shah, M. M. \& LaBeaud, A. D. Climate Change Could Shift Disease Burden from Malaria to Arboviruses in Africa. Lancet Planet. Health 4, e416-e423 (2020).

20. Carlson, C. J. et al. Climate change will drive novel cross-species viral transmission. BioRxiv 2020-01 (2021).

21. Cradock-Henry, N. A., Connolly, J., Blackett, P. \& Lawrence, J. Elaborating a systems methodology for cascading climate change impacts and implications. Methods X 7, 100893 (2020).

22. Quiggin, D., De Meyer, K., Hubble-Rose, L. \& Froggart, A. Climate change risk assessment 2021.1-49 www.chathamhouse.org/2021/09/climate-change-riskassessment-2021 (2021).

23. Kemp, L. A Systems Critique of the 2015 Paris Agreement on Climate. in Pathways to a Sustainable Economy (eds. Hossain, M., Hales, R. \& Sarker, T.) 25-41 (Springer International Publishing, 2018). doi:10.1007/978-3-319-67702-6_3.

24. Keys, P. W. et al. Anthropocene risk. Nat. Sustain. 2, 667-673 (2019)

25. Richards, C. E., Lupton, R. C. \& Allwood, J. M. Re-framing the threat of global warming: an empirical causal loop diagram of climate change, food insecurity and societal collapse. Clim. Change 164, 49 (2021).

26. Otto, I. M. et al. Social tipping dynamics for stabilizing Earth's climate by 2050. Proc. Natl. Acad. Sci. 117, 2354-2365 (2020).

27. Smith, S. R., Christie, I. \& Willis, R. Social tipping intervention strategies for rapid decarbonization need to consider how change happens. Proc. Natl. Acad. Sci. 117,10629 (2020)

28. Scheffer, M. et al. Anticipating Critical Transitions. Science 338, 344-348 (2012).
29. Scheffer, M., Carpenter, S., Foley, J. A., Folke, C. \& Walker, B. Catastrophic shifts in ecosystems. Nature 413, 591-596 (2001).

30. Xu, C., Kohler, T. A., Lenton, T. M., Svenning, J.-C. \& Scheffer, M. Future of the human climate niche. Proc. Natl. Acad. Sci. 117, 11350-11355 (2020).

31. Kemp, L. \& Cline, E. Systemic Risk and Resilience in the Bronze Age. in Historical Perspectives on Public Policy in Societal-Environmental Crises (Springer, 2021).

32. Biggs, R. et al. Toward Principles for Enhancing the Resilience of Ecosystem Services. Annu. Rev. Environ. Resour. 37, 421-448 (2012).

33. Walker, B., Salt, D. \& Reid, W. Resilience thinking: sustaining ecosystems and people in a changing world. (Island Press, 2012).

34. Folke, C., Biggs, R., Norström, A., Reyers, B. \& Rockström, J. Social-ecological resilience and biospherebased sustainability science. Ecol. Soc. 21, (2016).

35. Wilkinson, R. G. \& Pickett, K. The spirit level: why equality is better for everyone; [with a new chapter responding to their critics]. (Penguin Books, 2010).

36. Wilkinson, R. G. \& Pickett, K. The inner level: how more equal societies reduce stress, restore sanity and improve everyone's well-being. (Allen Lane, 2018).

37. Gupta, M. S. Does Corruption Affect Icome Inequality and Poverty? (International Monetary Fund, 1998).

38. Policardo, L. \& Carrera, E. J. S. Corruption Causes Inequality, or is it the Other Way Around? An Empirical Investigation for a Panel of Countries. Econ. Anal. Policy 59, 92-102 (2018).

39. Levitsky, S. \& Ziblatt, D. How democracies die. (Viking an imprint of Penguin Books, 2018).

40. Schleussner, C.-F., Donges, J. F., Donner, R. V. \& Schellnhuber, H. J. Armed-conflict risks enhanced by climate-related disasters in ethnically fractionalized countries. Proc. Natl. Acad. Sci. 113, 9216-9221 (2016). 


\section{THE COP26 UNIVERSITIES NETWORK}

This briefing is produced in association with the COP26 Universities Network, a growing group of more than 80 UK-based universities and research centres working together to help deliver an ambitious outcome at the UN Climate Summit in Glasgow and beyond.

The Climate Risk Notes series is an outcome of the Climate Risk Summit. The Summit aimed to bring key information on the risks of climate change, and their communication to decision-makers, to the attention of a wider audience ahead of COP26. The Climate Risk Notes crystallise and expand on the learnings from the Summit.

The briefing represents the views of its authors (listed on page one) and not necessarily that of every University or institution participating in the network. For more information about the COP26 Universities Network, please contact cop26universities@imperial.ac.uk

\section{图图 UNIVERSITY OF (N) CAMBRIDGE}

\section{HOW TO CITE THIS PAPER}

Kemp, L. (2021). The Cascading Climate Crisis. COP26 Universities Network Climate Risk Note. 